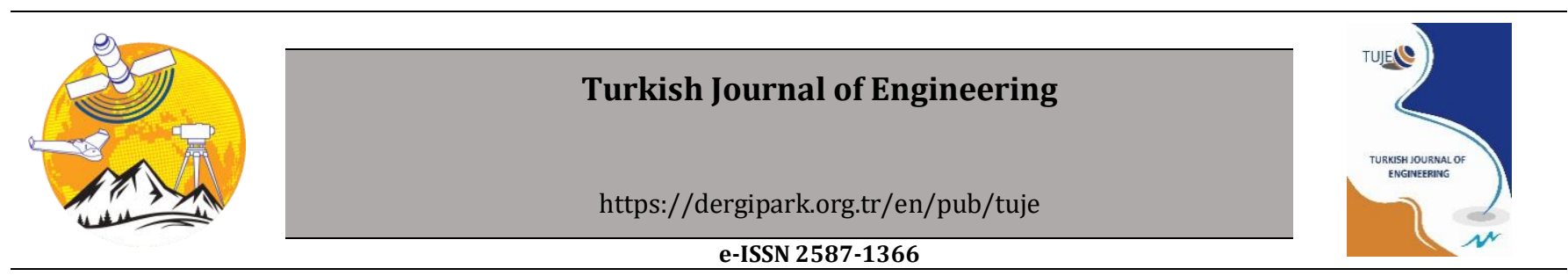

\title{
Modeling and simulation of dynamic mechanical systems using electric circuit analogy
}

\author{
Mehmet Akbaba *1 \\ ${ }^{1}$ Karabük University, Engineering Faculty, Computer Engineering Department, Karabük, Turkey
}

\author{
Keywords \\ Unified modeling \\ Simulation \\ Complex mechanical systems \\ Electric circuit \\ Analogy
}

\begin{abstract}
Modeling and simulation are prerequisite to analysis and design of engineering systems. Modern engineering systems often are multy disciplinary, i.e., may include blocks from different majors of engineering, such as electrical, mechanical, fluid, etc. Availability of a unified approach for system modeling will make it easy for engineers or researcher from a certain discipline to model the systems from other disciplines. For example, with availability of a unified modeling methodology an electrical engineer will be able to model a system composed of electrical, mechanical and fluid systems. Modeling of complex mechanical systems is not always easy for engineers from other disciplines. On the other hand, it is much easier to establish mathematical model of electric circuits. Furthermore, simulation software is much richer for electric circuits. Therefore, in this paper a methodology is proposed for unifying the modeling of electrical and complex mechanical systems by obtaining electric circuit model of complex mechanic systems. In developing the proposed methodology, analogy between the electrical and mechanical elements have been used as tools. Proposed methodology has been applied to modeling and simulation of a relatively complex mechanical system and benefits accrued from this approach has been discussed. It is further proposed that the approach presented in this paper can be easily extended to modeling of dynamic systems from other engineering disciplines.
\end{abstract}

\section{INTRODUCTION}

Modeling and simulation are prerequisite to the design of a dynamic system, because directly proceeding to the designing and manufacturing a system and then testing for expected performance would be inevitably expensive. Wide-spread availability of high speed and high storage capacity computers made the simulation process even more attractive. Modeling and simulation lie at the intersection between theory and experiment and highly valued in scientific discovery. Simulation provides additional insights that are often impractical or impossible to discover through real-world experimental and theoretical analysis alone. It could be viewed as virtual experimentation that could be implemented in any circumstances. Benefits of the modeling and simulation can be summarized as follows:

a) A simulation model executed on a computer system can compress the time frame in thousands of folds and can be used to investigate quickly the effects of a changes in a real-life situation that take place over several years.

b) Simulation could be used to study complex systems, that would be very difficult to investigate, without runing a simulation model on a fast digitalcomputer.

c) The effects of various changes on a complex systems performance can be easily investigated without producing a physical prototype.

d) Simulation culd be used to investigate situation that true hands-on experiments would be dangerous in real life

e) Optimization routines can be incorporated into the simulation models and system can be designed with optimum performance in various aspects.

There are several software packages available for simulation of mechanical systems such as MATLAB/Simulink toolbox SimMechanics (Hrankova 
and Pastor 2013; Virgala et al. 2013; SIMULA 2008; ANSYS 2008; COMSOL 2008). Also, there are many publications on modeling and simulation of mechanical systems such as (Macchelli et al. 2009; Dulau et al. 2016; Hussein 2015). Modeling of dynamic systems from each individual engineering specialization are given in several texts (Ogata and Yang 2002; Ogata 2004; Woods and Lawrence 1997; Dabney and Harman 2004; Close at al. 2002; Ljung and Glad 1994; Rowell and Wormley 1997).

However, modern engineering systems are often multy disciplinary, containing blocks from different engineering disciplines. As such, modeling of a multy disciplinary dynamic systems by an engineer or researcher from a single discipline will rise some difficulties. Therefore, availability of a unified modeling methodology will be much useful in modeling process. Towards this aim, in this paper a unified modelling methodology is proposed for unifying the modeling of electrical and mechanical systems by obtaining electrical circuit model of complex mechanical systems. In developing the methodology of proposed unified model, analogy between the electrical and mechanical elements, that are given in several text (Ogata 2004, Woods and Lawrence, 1997, Close at al. 2002), have been used as tools. It should be noted here that a reverse modeling methodology, i.e., modeling an electrical circuit as an equivalent mechanical system is also possible, which may be preferred by mechanical engineers.

The unified modeling methodology proposed in this paper, has been applied to modeling and subsequently simulation of a complex mechanical system. It has been shown that how the proposed approach simplifies the modeling of complex mechanical dynamic systems. The benefits accrued from proposed approach have been discussed. It is also proposed that the approach explained in this investigation can similarly be extended to the dynamic systems from other engineering disciplines.

\section{METHODOLOGY}

In translational mechanical systems there are three main system elements, which are mass (M), stiffness element $(\mathrm{K})$ and viscous friction element (B). The most common stiffness element is she spring, which will be considered in this paper. Corresponding elements in a rotational mechanical system are moment of inertia, rotational stiffness and rotational viscous friction. Similarly, in electrical systems there are well known three elements main that are inductance (L), capacitance (C) and resistance (R). The governing equations between mechanical and electrical systems show a complete similarity as shown in the Table 1 and Table 2 . This gives opportunity for a perfect analogy between mechanical and electrical systems. Based on this characteristic it is possible to develop unified modeling methodology for modeling complex dynamic mechanical systems in the form of electric circuits. Analogy given in Table 1 is known as direct analog or force-voltage analog in which each velocity corresponds to an electrical current and each displacement corresponds to an electrical charge (Ogata 2004).
Analogy between the governing equations of the mechanical and electrical elements given in Table 1 are written in Table 2 . It can be seen from Table 2 there is complete similarity between the governing equations of the mechanical and electrical elements. This gives opportunity for developing a unified modeling methodology between the two systems.

Table 1. Analogy between the electrical and mechanical elements

\begin{tabular}{|c|c|c|c|c|c|}
\hline Symbols & Mechanical & Unit & Symbols & $\begin{array}{l}\text { Electrical } \\
\text { Analog }\end{array}$ & Unit \\
\hline$f$ & Force & $\mathrm{N}$ & $E$ & Voltage & $\mathrm{V}$ \\
\hline$x$ & Disp. & $\mathrm{m}$ & $q$ & $\begin{array}{l}\text { Electrical } \\
\text { Charge }\end{array}$ & $\mathrm{C}$ \\
\hline$v$ & Speed & $\mathrm{m} / \mathrm{s}$ & $i$ & $\begin{array}{l}\text { Electric } \\
\text { Current }\end{array}$ & A \\
\hline$M$ & Mass & $\mathrm{kg}$ & $L$ & $\begin{array}{l}\text { Inductanc } \\
\mathrm{e}\end{array}$ & $\mathrm{H}$ \\
\hline$B$ & $\begin{array}{l}\text { Viscous } \\
\text { Friction }\end{array}$ & $\mathrm{Ns} / \mathrm{m}$ & $R$ & $\begin{array}{l}\text { Electrical } \\
\text { Resistance }\end{array}$ & $\Omega$ \\
\hline$K$ & Spring & $\mathrm{N} / \mathrm{m}$ & $\frac{1}{C}$ & Capacitor & $\mathrm{F}$ \\
\hline
\end{tabular}

Table 2. Governing equations of the mechanical and electrical elements given in Table 1

\begin{tabular}{lll}
\hline $\begin{array}{l}\text { Mechanical Elements and } \\
\text { governing equations }\end{array}$ & $\begin{array}{l}\text { Analogue Electrical } \\
\text { elements and analog } \\
\text { governing equations }\end{array}$
\end{tabular}

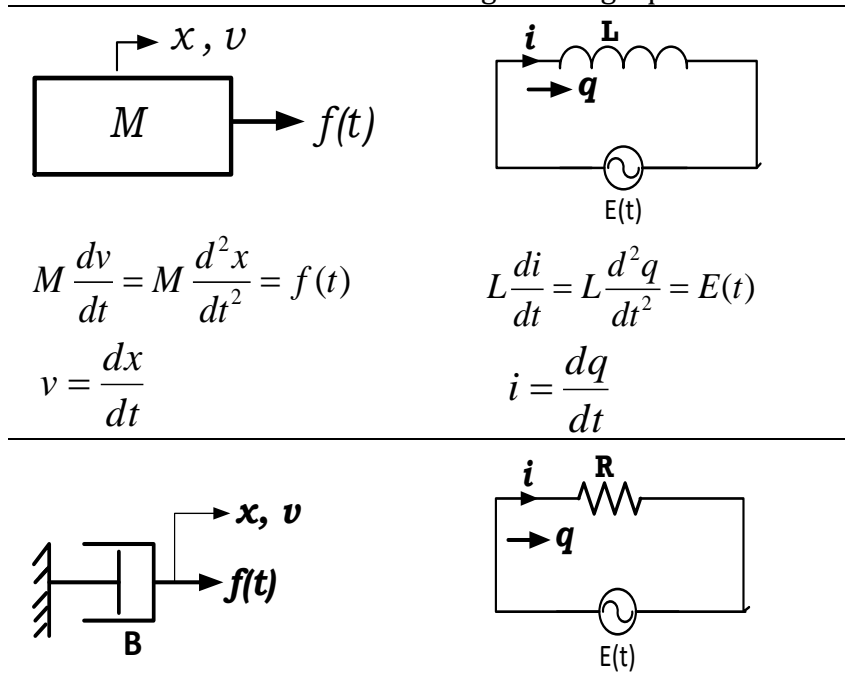

$$
B v=B \frac{d x}{d t}=f(t) \quad R i=R \frac{d q}{d t}=E(t)
$$
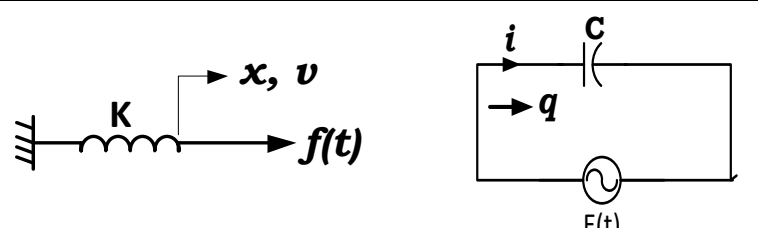

$$
\begin{aligned}
K x & =f(t)=K \int v d t & \frac{q}{C} & =E(t)=\frac{1}{C} \int i d t \\
x & =\int v d t & \mathrm{q} & =\int i d t
\end{aligned}
$$

The analogy between the physical elements and related governing equations given in tables 1 and 2 clearly show that there is a complete similarity between the two systems. Therefore, the two systems always can virtually represent each other. 
The key elements in developing a unified modeling methodology is the form of organizing the interconnects between the different blocks of the mechanical systems, in the corresponding equivalent electrical circuits. These key elements can be laid down as follows:

a) Each mass in a mechanical system corresponds to a circuit loop in the equivalent electrical circuit. Therefor the number of loops in the equivalent electrical circuit is defined by the number of different masses in the mechanical system.

b) The interconnect elements in each mass block in mechanical systems corresponds to the electrical elements shared between the equivalent electrical circuit loops.

c) In a mechanical system the series connected elements carrying the same value of force correspond to the parallel connected elements in the equivalent electric circuit.

d) In a mechanical system velocity of each mass corresponds to the each loop current in the equivalent electrical circuit.

e) In a mechanical system displacement of a mass corresponds to the total electrical charge accumulated on each associated capacitor in the equivalent electrical circuit.

f) In a mechanical system the displacement difference between the two masses corresponds to the total charge on the associated capacitor placed on the branch of equivalent electric circuit that is common to the loops associated with each mass.

\section{APPLICATION AND DICUSSIONS}

An example mechanical system is shown in Fig. 1.

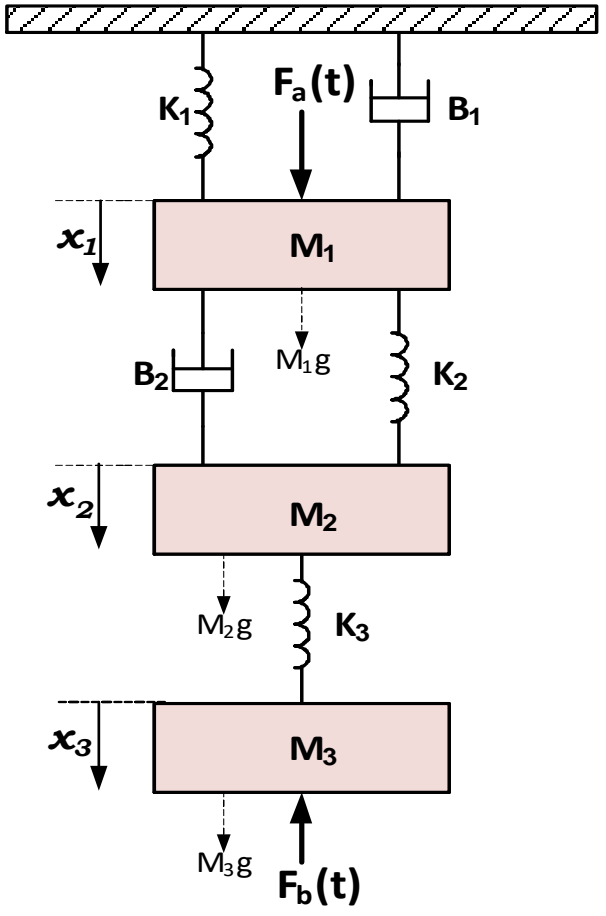

Figure 1. Example suspended mechanical system

A suspended system is selected in order in which the gravitational forces can be accounted for. The gravitational forces are shown as $\mathrm{M}_{1} \mathrm{~g}, \mathrm{M}_{2} \mathrm{~g}$ and $\mathrm{M}_{3} \mathrm{~g}$ respectively, where $\mathrm{g}$ is the usual gravitational acceleration ( $\left.\mathrm{g}=9.8 \mathrm{~m} / \mathrm{s}^{2}\right)$. If references for displacements $x_{1}, x_{2}$ and $x_{3}$ are taken as the positions of the masses, before application of the external forces $\mathrm{Fa}(\mathrm{t})$ and $\mathrm{Fb}(\mathrm{t})$, but after the system being suspended and the sprigs are lengthened, i.e., as the first equilibrium position is attained, then all the gravitational forces can be dropped from the model equations. In this case the model equations of a suspended systems become like the model equations of a translational systems. Therefore, the way of modelling applied to the suspended system in hand will be equally valid for translational systems as well. In this case values of the displacement and velocities of the masses can be taken as zero.

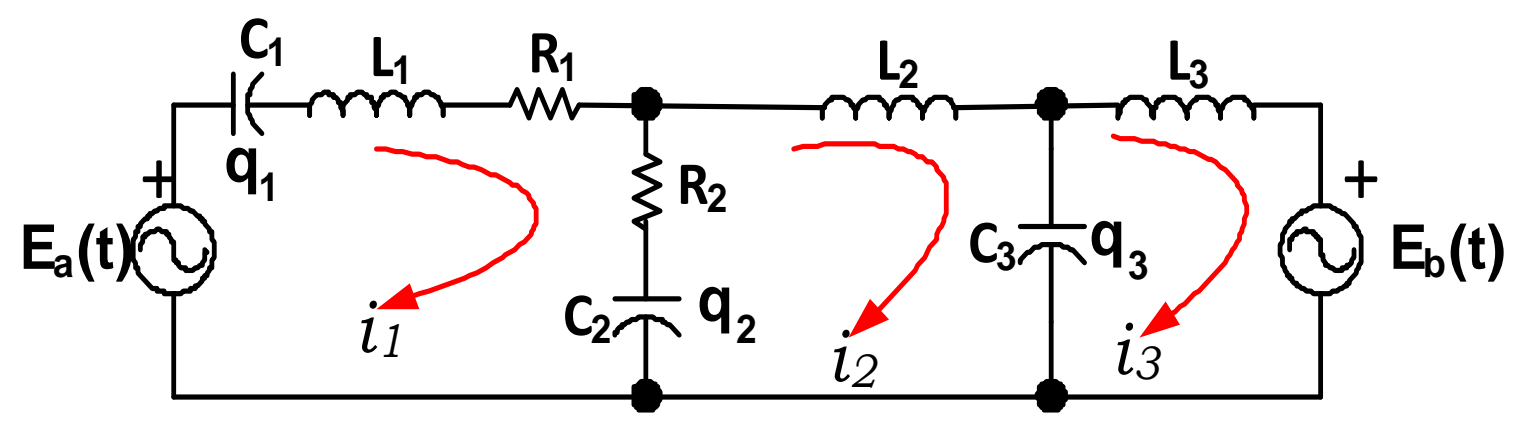

Figure 2. Equivalent Electrical circuit of the mechanical system given in Figure 1

Applying the principles of the analogy that have been explained earlier in section 2.1, the electrical equivalent circuit of the mechanical system given in Fig. 1 will be as shown in Fig. 2:

The system parameters are selected as: $\mathrm{M}_{1}=18 \mathrm{~kg}$, $\mathrm{M}_{2}=12 \mathrm{~kg}, \mathrm{M}_{3}=9 \mathrm{~kg}, \mathrm{~K}_{1}=220 \mathrm{~N} / \mathrm{m}, \mathrm{K}_{2}=350 \mathrm{~N} / \mathrm{m}, \mathrm{K}_{3}=200$ $\mathrm{N} / \mathrm{m}, \mathrm{B}_{1}=20 \mathrm{Ns} / \mathrm{m}, \mathrm{B}_{2}=15 \mathrm{Ns} / \mathrm{m}$ and the two applied forces are selected as:

$$
\begin{aligned}
& F_{a}(t)=60 \sin (2 t) e^{-0.1 t}+120 N \text { and } \\
& F_{b}(t)=30 \cos (2 t) e^{-0.08 t}+20 N
\end{aligned}
$$

Applying the principles of the analogy that have been explained earlier in section 2.1, the electrical equivalent circuit of the mechanical system given in Fig. 1 will be as shown in Fig. 2: 
Source voltages $E_{a}(t)$ and $E_{b}(t)$ in Fig. 2 are corresponding to the applied forces $F_{a}(t)$ and $F_{b}(t)$ respectively.

At the beginning the system was in equilibrium position and at instant $\mathrm{t}=0$ both forces are applied simultaneously.

The amplitudes of equivalent electrical circuits parameters naturally are $\mathrm{L}_{1}=\mathrm{M}_{1}, \mathrm{~L}_{2}=\mathrm{M}_{2}, \mathrm{~L}_{3}=\mathrm{M}_{3}, \mathrm{C}_{1}=1 / \mathrm{K}_{1}$

$\mathrm{C}_{2}=1 / \mathrm{K}_{2}, \mathrm{C}_{3}=1 / \mathrm{K}_{3}, \mathrm{R}_{1}=\mathrm{B}_{1}, \mathrm{R}_{2}=\mathrm{B}_{2}, \mathrm{E}_{\mathrm{a}}(\mathrm{t})=\mathrm{F}_{\mathrm{a}}(\mathrm{t})$ and $\mathrm{E}_{b}(\mathrm{t})=\mathrm{F}_{\mathrm{b}}(\mathrm{t})$. Equations governing the circuit given in Fig. 2 will be as follows:

$$
\begin{aligned}
& E_{a}(t)=\left(R_{1}+R_{2}\right) i_{1}+L_{1} \frac{d i_{1}}{d t}+\frac{q_{1}}{C_{1}}+\frac{q_{2}}{C_{2}}-R_{2} i_{2} \\
& 0=-R_{2} i_{1}+R_{2} i_{2}-\frac{q_{2}}{C_{2}}+L_{2} \frac{d i_{2}}{d t}+\frac{q_{3}}{C_{3}} \\
& -E_{b}(t)=-\frac{q_{3}}{C_{3}}+L_{3} \frac{d i_{3}}{d t} \\
& \frac{d q_{1}}{d t}=i_{1}
\end{aligned}
$$

$$
\left[\begin{array}{c}
\frac{d i_{1}}{d t} \\
\frac{d i_{2}}{d t} \\
\frac{d i_{3}}{d t} \\
\frac{d q_{1}}{d t} \\
\frac{d q_{2}}{d t} \\
\frac{d q_{3}}{d t}
\end{array}\right]=\left[\begin{array}{ccccc}
-\frac{R_{1}+R_{2}}{L_{1}} & \frac{R_{2}}{L_{1}} & 0 & -\frac{1}{L_{1} C_{1}} & -\frac{1}{L_{1} C_{2}} \\
\frac{R_{2}}{L_{2}} & -\frac{R_{2}}{L_{2}} & 0 & 0 & \frac{1}{L_{2} C_{2}} \\
0 & 0 & 0 & 0 & 0 \\
1 & 0 & 0 & 0 & 0 \\
1 & -1 & 0 & 0 & 0 \\
0 & 1 & -1 & 0 & 0
\end{array}\right.
$$

Equation (8) can be solved by any numerical method or can be solved by using MATLAM/Simulink (Danbey and Harman, 2004). In this paper $4^{\text {th }}$ order Runge-Kutta method has been selected as solution tool (Chapra and Canale 2010) and MATLAB is used for programming.

The simulation results are shown in Fig. 3 for the velocities of the three masses.

Examination of the Fig. 3 shows that when the system attains new equilibrium position velocities of the 3 masses becomes zero, which is the expected natural results. This shows the success of the proposed unified modeling approach. Therefor expected correct results are obtained without deriving real mechanical equations.

A new equilibrium position established because as the time progressed the decaying sine and cosine terms in force expressions becomes zero and only the constant components remains. Fig. 3 also shows that, although the larger force on the top side has much higher constant term than the amplitude of exponentially decaying component ( 60 to $120 \mathrm{~N}$ ), the velocity of the middle mass attains higher value then the velocities of the both top

$$
\begin{aligned}
\frac{d q_{2}}{d t} & =i_{1}-i_{2} \\
\frac{d q_{3}}{d t} & =i_{2}-i_{3}
\end{aligned}
$$

Organizing the above six simultaneous differential equations into State-Space model (Ogata and Yang 2002; Ogata 2004) one obtains:

$$
\begin{aligned}
& \dot{x}(t)=A x(t)+B u(t) \\
& y(t)=C x(t)+D u(t)
\end{aligned}
$$

Where $A$ is the system matrix, $B$ is the input matrix, $\mathrm{C}$ is the output matrix, $x(\mathrm{t})$ are the state variables, $y(t)$ are the output variables and $u(t)$ are the input forcing functions. For the system in hand the open form of these matrixes is given in equation (8). The matrices A, B and $u(t)$ are available from equation (8). The outputs are taken as state variables themselves then the matrix $D$ is a 6 by 2 zero matrix and matrix $C$ is a 6 by 6 unity diagonal matrix.

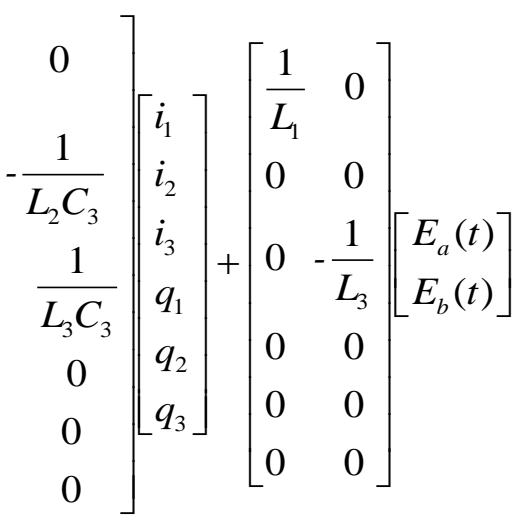

and bottom masses, because the middle mass is affected by the vibration of both the top and bottom masses which are under the transient force components that are displaced from each other by $90^{\circ}$ time phase difference (sine and cosine terms are displaced by $90^{\circ}$ ).

The simulation results are shown in Fig. 4 for the displacements of the three masses.

Fig. 4 shows that the displacements exhibit large excursions between positive and negative values. These large excursions in the displacements are the combined results of the effect of the phase difference between the sinusoidal components of the applied forces and the natural vibrations arising from sudden application of the forces. From Fig. 4 also can be observed that mass M1 which is under lager force has much higher positive displacement and higher steady-state displacement, which is a further proof of the correctness of the applied approach. 

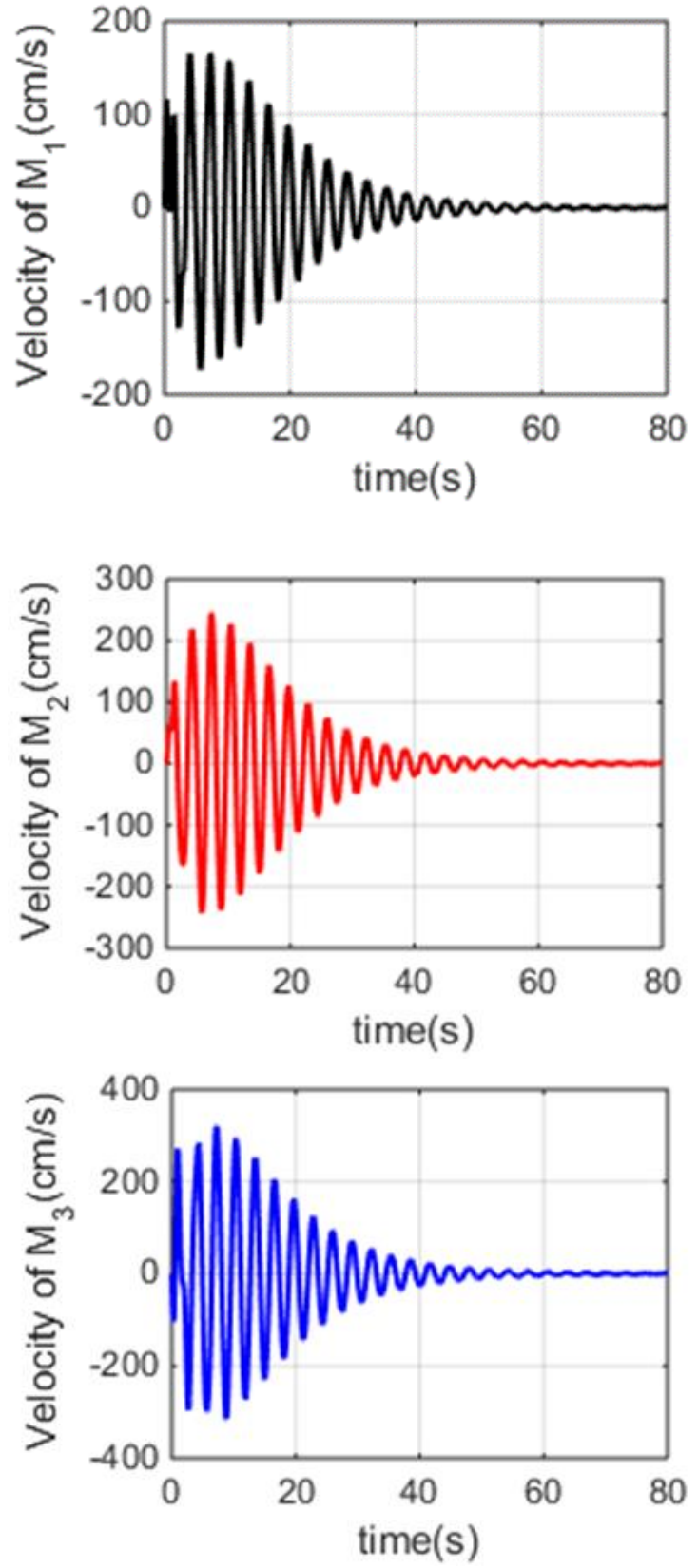

Figure 3. Velocities of the 3 masses $M_{1}, M_{2}$ and $M_{3}$

To verify that the effect of phase difference in the exponentially decaying sinusoidal components of the forces, the displacements are re-determined by removing the above said phase difference, i.e., converting the cosine term to sine term in $F_{b}(t)$, where forces are expressed as:

$$
\begin{aligned}
& F_{a}(t)=60 \sin (2 t) e^{-0.1 t}+120 N \text { and } \\
& F_{b}(t)=30 \sin (2 t) e^{-0.08 t}+20 N
\end{aligned}
$$

The displacements computed under this condition is presented in Fig. 5. It can be observed from this figure that when keeping all force amplitudes same as before but removing only the phase difference between the forces, the large excursions in the displacements are greatly reduced. On the other hand, the settling time is shortened to a large extent. The remaining transient components are almost the result of natural vibration arising from sudden application of the forces.
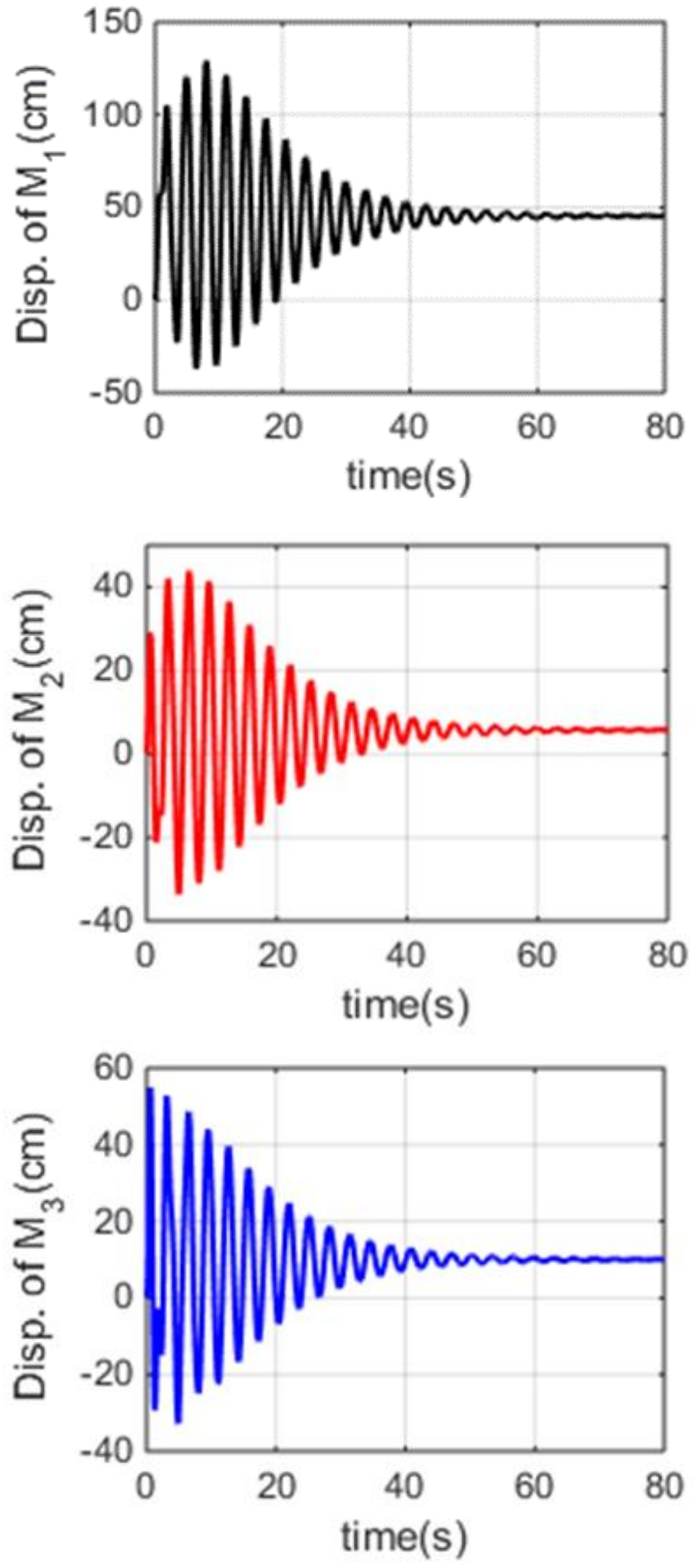

Figure 4. Displacement of the 3 masses $M_{1}, M_{2}$ and $M_{3}$

It can be observed From Figs. 4 and 5 that the final steady-state values of the displacements are same in both cases $(46.4 \mathrm{~cm}, 5.7 \mathrm{~cm}$ and $9.8 \mathrm{~cm}$ respectively), i.e., they are not affected by the decaying components of the forces. Only the constant terms $(120 \mathrm{~N}$ and $20 \mathrm{~N})$ are effective on the steady-state values of the displacements.

To verify the above arguments further, the exponentially decaying sinusoidal components are removed from force expressions and displacements are recalculated, i.e., when force expressions are:

$F_{a}(t)=120 N$ and

$F_{b}(t)=20 N$

Results of these calculations are plotted in Fig. 6. 

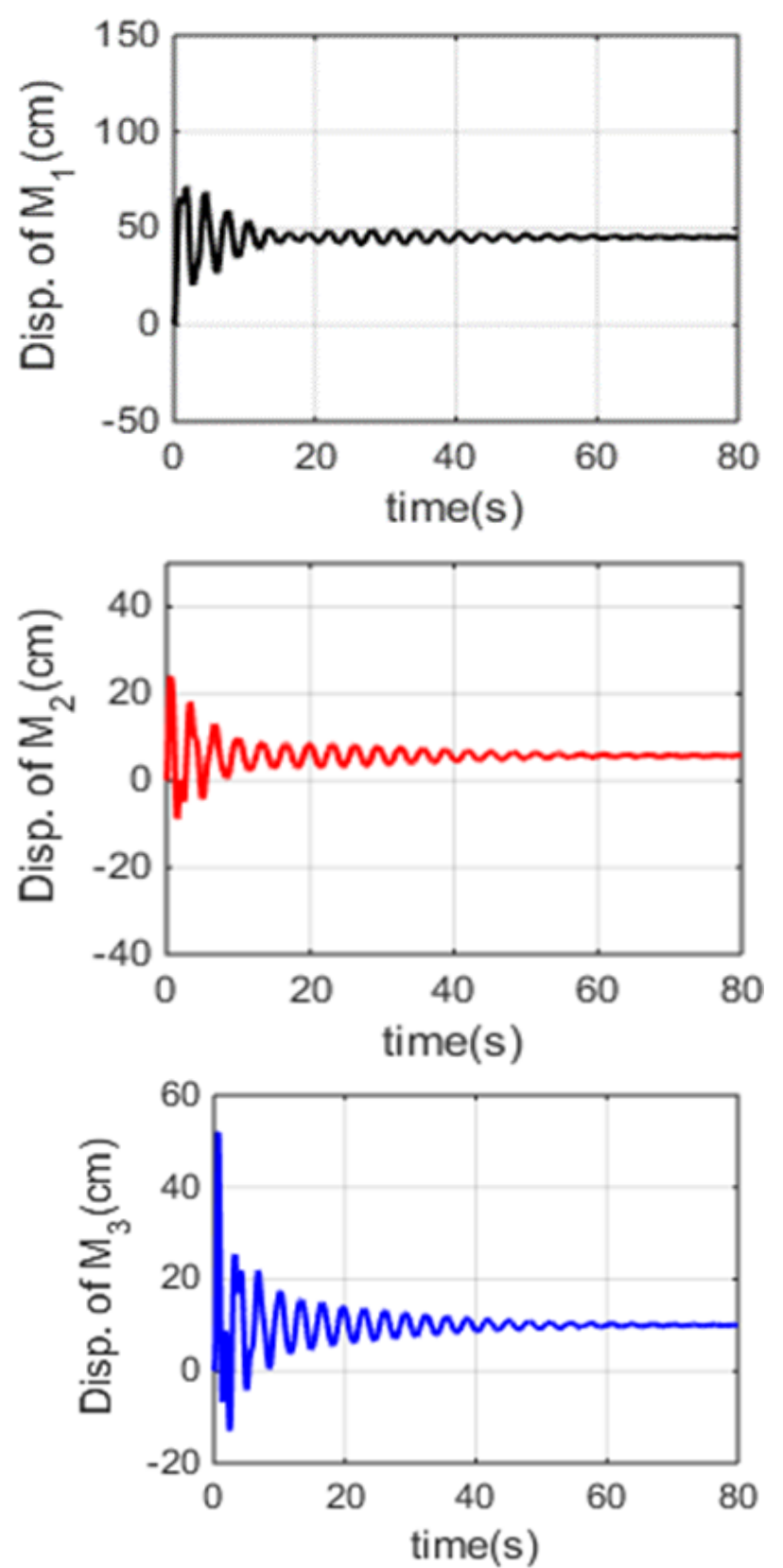

Figure 5. Displacements of the three masses under new set of forces (amplitudes are same as before but the phase difference between the forces are removed).

Comparison of the figs. 5 and 6 show that the results are almost same in both cases. There are only minor differences in the transient portions of the displacements. This clarifies all the above argument regarding the phase difference between the applied forces.

An experienced system engineer could easily identify that the obtained results are well in lie with the expected results.

The proposed unified modeling methodology can easily be extended to some other dynamic engineering systems such as the fluid systems. Analogy between the basic three elements of the electric systems and the basic fluid quantities, fluid resistance, fluid capacitance and fluid inductance or inertance and also analogy between their governing equations are given in (Close et al. 2002; Woods and Lawrence 1997).
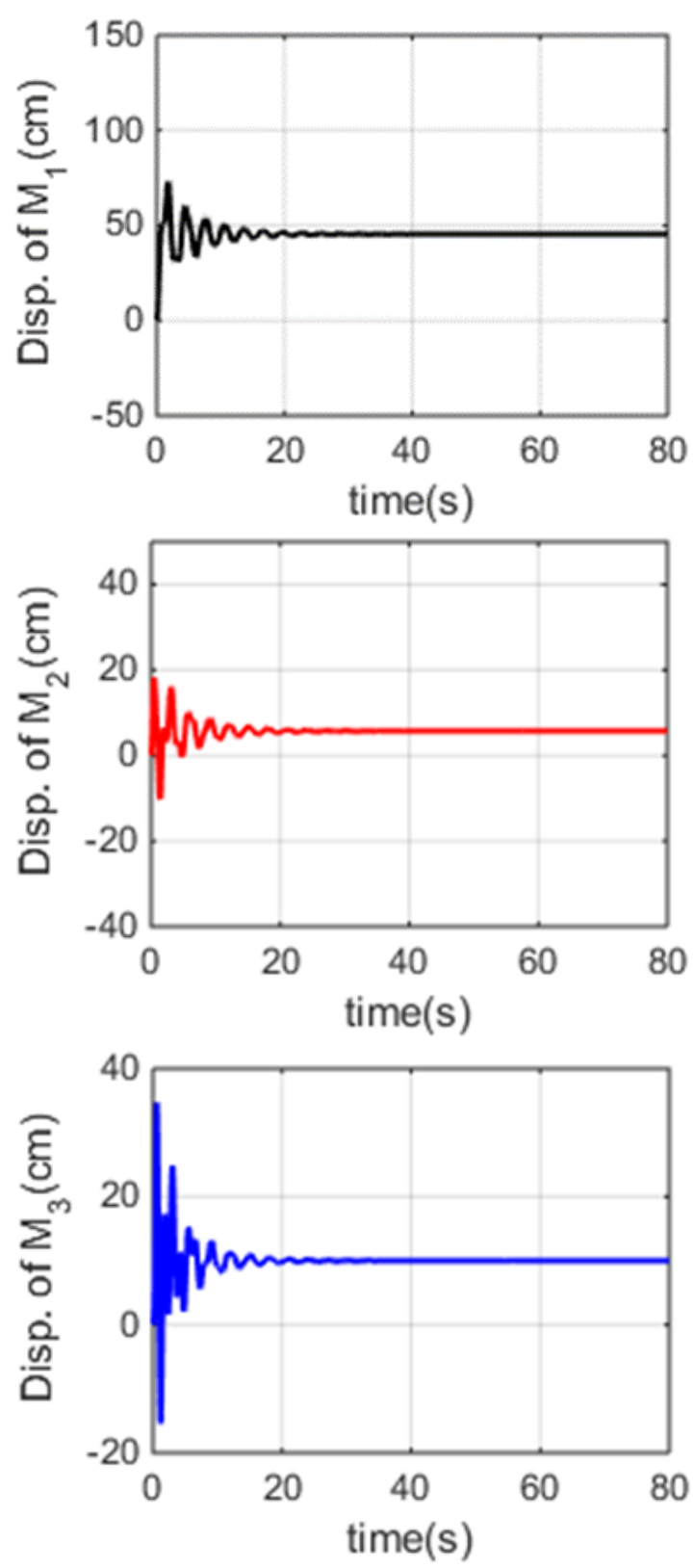

Figure 6. Displacements of the three masses under when $\mathrm{F}_{\mathrm{a}}(\mathrm{t})=120 \mathrm{~N}$ and $\mathrm{F}_{\mathrm{b}}(\mathrm{t})=20 \mathrm{~N}$

\section{CONCLUSION}

In this paper a unified modeling methodology has been proposed for unifying the modeling of dynamic mechanical systems and electrical systems. Electrical circuits has been taken as the base system and modeling dynamic mechanical systems are modelled as electrical circuit. The unified modeling methodology is based on the analogy between the corresponding basic elements in the mechanical and electrical systems. The main elements of the proposed unified modeling methodology have been laid down in details and then it has been applied to modeling and subsequently simulation of a relatively complex dynamic mechanical system. It is shown how a complex dynamic mechanical system can be easily modelled as electrical circuit, without deriving the true mechanical equations, for example going through free body diagrams, which is not always easy for engineers or researches whose are not mechanical engineers. Further the proposed methodology is benefiting from the relatively easy modeling of electrical 
circuits. Simulation has been performed for different forms of applied forces and expected results were obtained at each case. This gives confidence about the proposed unified modeling methodology.

Similar unified modeling methodology can be easily extended to dynamic systems from other engineering systems such as fluid systems.

It is also recommended that the prosed methodology could be useful to the practicing engineers and educational purposes.

\section{REFERENCES}

ANSYIS Inc. (2008). ANSYS Multiphysics (Online). Available: http:// www.ansys.com/.

Chapra S C \& Canale R P (2010). Numerical Methods for Engineers. $6^{\text {th }}$ edition. McGraw Hill, New York, USA.

Close C M, Frederic D K \& Newell J C (2002). Modelling and Simulation of Dynamic Systems. John Wiley \& Sons Inc., NewYork, USA. ISBN: 978-0471394426

COMSOL Group (2008). "COMSOL Multiphysics (Online)”, Available: http:// www.comol.com/.

Dabney J B \& Harman T L (2004). Mastering Simulink. Pearson Prentice Hall, New Jersey, USA. ISBN: 9780131424777

Dulau M, Oltean S E \& Duka A V (2016). Modeling and simulation of the operation mechanical systems which is affected by uncertainties. Procedia Technology, 22, 662-669. DOI: 10.1016/j.protcy.2016.01.139

Hrankova D \& Pastor M (2013). Mechanical Systems a SimMechanis Simulation. American Journal of Mechanical Engineering, 1(7), 251-255. DOI: 10.12691/ajme-1-7-20
Ljung L \& Glad T (1994). Modeling Dynamic Systems. Prentice Hall, Englewood Cliffs, New Jersey, USA.

Macchelli A, Melchiorri C \& Stramigioli S (2009). Portbased modelling of mechanical systems with rigid and flexible links. IEEE Transactions on Robotics, 25(5), 1016-1029. DOI: 10.1109 /TRO.2009.2026504

Hussein M T (2015). Modeling mechanical and electrical uncertain systems using functions of rOBUST control MATLAB ToolBox. International Journal of Advanced Computer Science and Applications (IJACSA), 6(4), 79-84.

Ogata K (2004). System Dynamics. Prentice Hall, Englewood Cliffs, New Jersey, USA.

Ogata K \& Yang Y (2002). Modern Control Engineering. Prentice Hall, Englewood Cliffs, New Jersey, USA.

Rowell D \& Wormley D N (1997). System Dynamics. Prentice Hall, Englewood Cliffs, New Jersey, USA. ISBN: 978-0132108089

SIMULA (2008). Abaqus Unified (Online). Available: http:// www.simula.com/.

Virgala I, Franskowsky P \& Kenderova M (2013). Friction Effect Analysis of a DC Motor. American Journal of Mechanical Engineering, 1(1), 1-5. DOI: 10.12691/ajme-1-1-1

Woods R L \& Lawrence K L (1997). Modeling and Simulation of Dynamic Systems. Prentice Hall, Englewood Cliffs, New Jersey, USA. ISBN: 9780133373790

(C) Author(s) 2021.

This work is distributed under https://creativecommons.org/licenses/by-sa/4.0/ 